\title{
Conjunctive schedules of reinforcement IV: Effects on the pattern of responding of changes in requirement at reinforcement
}

\author{
JONATHAN L. KATZ and JAMES E. BARRETT \\ University of Maryland, College Park, Maryland 20742
}

\begin{abstract}
The effects of different schedule requirements at reinforcement on patterns of responding by pigeons were assessed under conjunctive schedules with comparable response-number requirements. Under one conjunctive schedule (conjunctive fixed-interval fixed-ratio schedule), a response was reinforced after a 6-min interval had elapsed and a specific minimum number of responses had been emitted. Under a second conjunctive schedule, a response was reinforced after the 6-min fixed interval and upon completion of a tandem schedule requirement (conjunctive fixed-interval tandem schedule). This schedule retained the same required minimum number of responses as the first conjunctive schedule, but responses were never reinforced according to a fixed-ratio schedule; the tandem schedule was comprised of a fixed-ratio and a small $(.1$ to $10.0 \mathrm{sec})$ fixed-interval schedule. Under the conjunctive fixed-interval fixedratio schedule, responding was characterized by an initial pause, an abrupt transition to a high response rate, and a second transition to a lower rate that prevailed or slightly increased up to reinforcement. Under the conjunctive fixed-interval tandem schedule, pauses were extended, response rates were lower, and the initial high rate of responding was generally absent. The above effects depended upon the size of the fixed interval of the tandem schedule. The distinct pattern of responding generated by conjunctive fixed-interval fixed-ratio schedules depends upon occasional reinforcement of fixed-ratio responding and not merely on the addition of a minimum number of required responses.
\end{abstract}

Conjunctive schedules of reinforcement specify at least two schedule requirements that must be met, in any order, prior to reinforcement. Under conjunctive fixed-interval fixed-ratio (conjunctive FI FR) schedules, reinforcement occurs only after a fixed period of time has elapsed (FI) and a fixed minimum number of responses (FR) have been emitted (Herrnstein \& Morse, 1958). The common pattern of responding maintained under this schedule is characterized by an initial pause, an abrupt transition to a high response rate, and a subsequent transition to a lower rate that prevails or slightly increases up to reinforcement (Barrett, 1974, 1975; Herrnstein \& Morse, 1958). This pattern of responding is of interest because rates of responding are typically highest well before reinforcement and subsequently decline, an exception to the general finding of increasing response rates under schedules in which interreinforcement times are more or less constant (Dews, 1970).

Supported in part by U.S. PHS Grants AA-02104, DA-01839, and MH-14275. We thank L. R. Gollub, W. H. Morse, R. D. Spealman, and J. M. Witkin for comments on earlier versions of this manuscript, and Nancy Gehman and Lynda Levy for secretarial assistance. Reprints may be obtained from either author. J.L. Katz's present address: Laboratory of Psychobiology, Department of Psychiatry, Harvard Medical School, 25 Shattuck Street, Boston, Massachusetts 02115.
Patterns of responding engendered under conjunctive FR FI schedules have some inherent instability due to interactions between the scheduled response requirements and ongoing behavior at the moment that responses are reinforced. When overall response rates are low, and especially when pauses are long, reinforcement occurs after the completion of the fixed-ratio schedule. Reinforcement according to the fixed-ratio schedule may then increase subsequent response rates so that responding is then reinforced according to the fixed-interval schedule. With reinforcement according to the fixed-interval schedule, response rates may eventually become low enough so that reinforcement occurs according to the fixed-ratio schedule (Herrnstein \& Morse, 1958). Dynamic interactions such as these may be important for the development of orderly sequences of responding.

The present study directly examined the effects on patterns and rates of responding exerted by reinforcement according to the FR requirement under conjunctive FI FR schedules. This was accomplished by imposing a short FI schedule in tandem with the FR requirement. Thus, reinforcement immediately following completion of the FR requirement was precluded on those occasions when the interval elapsed prior to completion of the FR schedule. This use of tandem schedules, which arrange reinforcement after a succession of schedule requirements are met, 
has been productive in analyzing the behavioral effects of contingencies of reinforcement and schedulecontrolled behavior (Ferster \& Skinner, 1957, Chap. 8; Morse, 1966). Particular arrangements of tandem schedules can selectively modify aspects of reinforcement schedules and can provide information on controlling features of reinforcement contingencies operating under single schedule conditions. In the present study, the conjunctive FI tandem schedule required the same minimum number of responses as the conjunctive FI FR schedule, but precluded reinforcement directly upon completion of the FR requirement. In this manner, it was possible to determine the specific contribution to patterns and rates of responding of the FR reinforcement contingencies under conjunctive schedules.

\section{METHOD}

\section{Subjects}

Four adult White Carneaux pigeons (P-2W, P-10, P-25, and P-233) were maintained at approximately $80 \%$ of their unrestrictedfeeding weights. Two pigeons (P-2W, P-233) were experimentally naive at the beginning of these experiments. The other two had had experience under a variety of schedules of food presentation; one of them (P-10) had been studied under conjunctive schedules (Barrett, 1974, 1975).

\begin{abstract}
Apparatus
Experiments were conducted in a single-key pigeon chamber modeled after those described by Ferster and Skinner (1957). A response key (R. Gerbrands Co., Arlington, Mass.) was centered on the aluminum front panel, $23 \mathrm{~cm}$ above the floor of the chamber. A peck on the key exceeding $15 \mathrm{~g}(.15 \mathrm{~N})$, defined a response and produced an audible click of a relay mounted behind the panel. Directly below the key $(18 \mathrm{~cm})$ was an opening through which food (4-sec access to mixed grain) could be provided. Food presentation was accompanied by a darkening of the two $7.5-\mathrm{W}$ green lamps which transilluminated the key and by illumination of the grain magazine. The chamber was placed in a ventilated sound-attenuating enclosure, which was equipped with white masking noise. Electromechanical programming and recording equipment was located in an adjoining room.
\end{abstract}

\section{Procedure}

The keypecking response was initially established by reinforcing with food successive approximations to pecking (P-2W,
P-233). For P-2W, P-25, and P-233, responding was maintained under an FI 6-min schedule by the 16th session; the first response after 6 min elapsed produced food. After at least 19 sessions under the FI 6-min schedule, the subjects were studied under the conjunctive schedules. Under one conjunctive schedule, food was presented after $6 \mathrm{~min}$ had elapsed (FI 6-min) and a tandem (tand) schedule requirement was completed; under the tandem schedule, the emission of $n$ responses initiated a short $(.1-10 \mathrm{sec})$ fixed interval [conjunctive (FI 6-min) (tand) FR n FI t)]. If the 6-min FI elapsed prior to the completion of the tandem requirement, food was presented according to the tandem schedule. If the 6-min interval had not elapsed prior to the completion of the tandem requirement, food presentation was provided according to the FI 6-min schedule. During various stages of the experiment, the FI of the tandem schedule was successively deleted (conjunctive FI 6-min FR $n$ ) and reinstated. The fourth pigeon (P-10) was intially studied under the conjunctive FI 6-min FR 51 schedule, after which the short FI was added and subsequently deleted. With two pigeons, parameters of the tandem schedule were varied over a range of values. Table 1 shows the sequence of conditions and session numbers under each condition for individual pigeons. Sessions ended after 20 food presentations and were conducted once daily (Monday through Friday). Schedules were changed when performances were stable over at least a fivesession period.

\section{RESULTS}

Patterns of responding engendered by the two conjunctive schedules are shown in the cumulative records (Figure 1); the upper and lower records for each pigeon show representative performances under the conjunctive FI FR schedule and conjunctive FI tandem schedules, respectively. Under the conjunctive FI FR schedule, a pause was followed by an abrupt transition to a high response rate which subsequently decreased after the emmission of some number of responses, typically greater than that required by the fixed-ratio schedule (e.g., at those portions of the records marked a). Occasionally, the initial pause was longer than 6 min and food was presented directly upon completion of the fixed-ratio requirement; in those instances, food was presented immediately after the period of responding at a high rate (e.g., at those portions of the records marked b). Under the conjunctive FI tandem schedule, initial pauses

Table 1

Sequence of Experimental Conditions and Session Numbers at Each Condition

\begin{tabular}{|c|c|c|c|c|}
\hline \multirow[b]{2}{*}{ Schedule } & \multicolumn{4}{|c|}{ Sessions } \\
\hline & P-2W & P-10 & P.25 & P-233 \\
\hline FI $6 \mathrm{~min}$ & $1-35$ & & $1-41$ & $1-19$ \\
\hline Conjunctive (FI $6 \mathrm{~min})(\operatorname{tand} \mathrm{FR} 50 \mathrm{FI} 10 \mathrm{sec})$ & $36-87$ & & $42-93$ & $20-68$ \\
\hline Conjunctive (FI $6 \mathrm{~min}$ ) (FR 51) & $88-187$ & $1-110$ & $94-148$ & $69-126$ \\
\hline Conjunctive (FI $6 \mathrm{~min}$ ) (tand FR $50 \mathrm{FI} 10 \mathrm{sec}$ ) & $188-210$ & $111-136$ & $149-205$ & $127-174$ \\
\hline Conjunctive (FI $6 \mathrm{~min})(\operatorname{tand}$ FR $150 \mathrm{FI} 10 \mathrm{sec}$ ) & & & & $175-194$ \\
\hline Conjunctive (FI $6 \mathrm{~min}$ ) (tand FR 75 FI $10 \mathrm{sec})$ & & & & $195-221$ \\
\hline Conjunctive (FI $6 \mathrm{~min}$ ) (FR 76) & & & & $222-313$ \\
\hline Conjunctive (FI $6 \mathrm{~min}$ ) (tand FR $75 \mathrm{FI} 10 \mathrm{sec}$ ) & & & & $314-328$ \\
\hline Conjunctive (FI $6 \mathrm{~min}$ ) (tand FR 50 FI $1 \mathrm{sec}$ ) & & & $206-225$ & \\
\hline Conjunctive (FI $6 \mathrm{~min}$ ) (tand FR $50 \mathrm{FI} .3 \mathrm{sec}$ ) & & & $226-245$ & \\
\hline Conjunctive (FI $6 \mathrm{~min}$ ) (tand FR 50 FI .1 sec) & & & $246-281$ & \\
\hline Conjunctive (FI $6 \mathrm{~min}$ ) (FR 51) & $211-254$ & $137-185$ & $282-333$ & \\
\hline Conjunctive (FI $6 \mathrm{~min}$ ) (tand FR $50 \mathrm{FI} .1 \mathrm{sec}$ ) & & & $334-346$ & \\
\hline
\end{tabular}




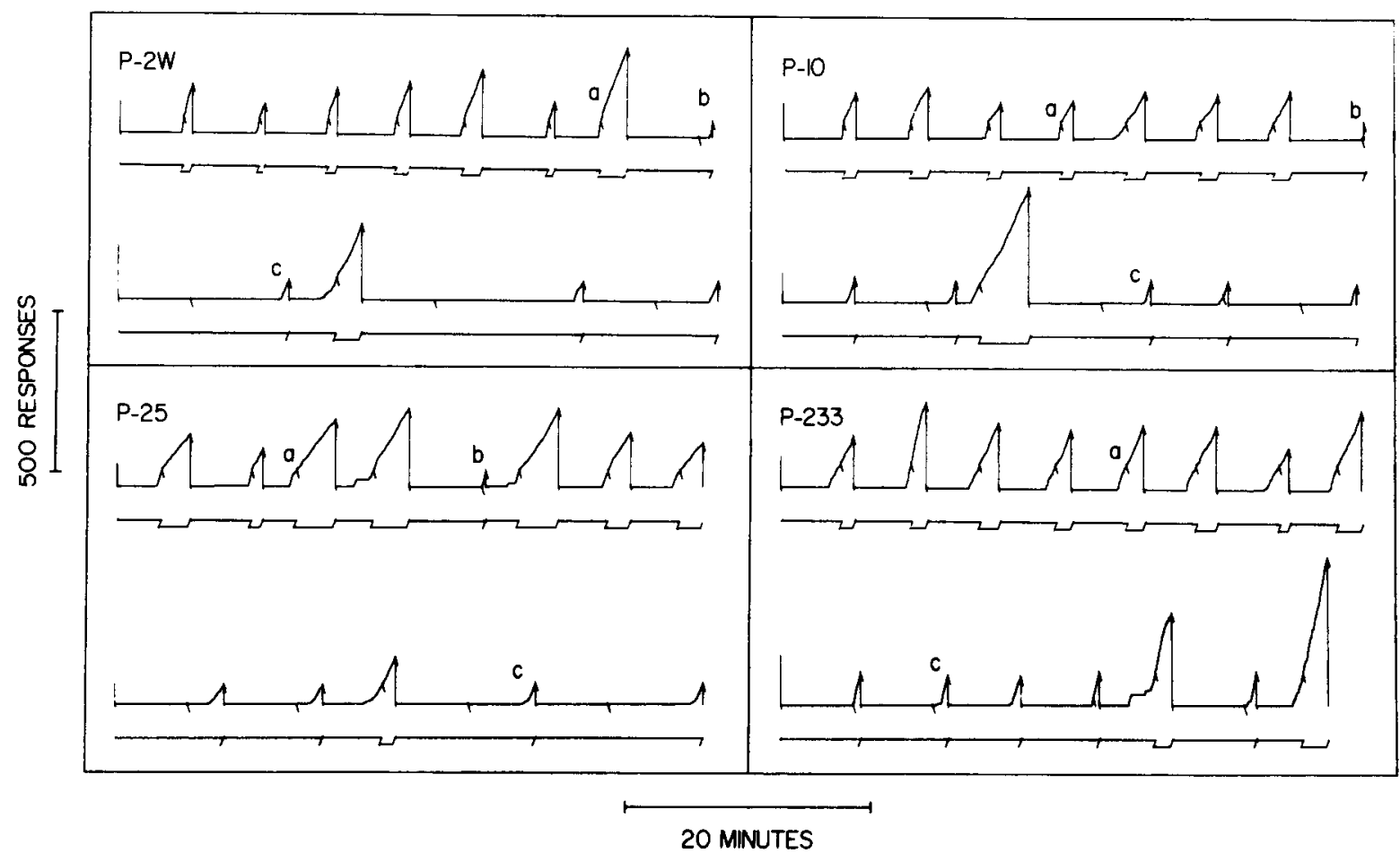

Figure 1. Cumulative records of responding under the two conjunctive schedules. Abscissae, time; ordinates, cumulative responses. The upper and lower records for each pigeon are representative records from portions of a session under the conjunctive FI FR schedule and conjunctive FI tand FR FI schedule, respectively. The records are from the first exposure to those schedules, except for the conjunctive FI FR record for P-10, which is from the second exposure to that condition. For all pigeons, the FI value was $6 \mathrm{~min}$; the FR values were 51 for P-2W, P-25, and P-10, and 76 for P-233. The tandem schedule was comprised of FR 50 and FI 10-sec for P-2W, P-25, and P-10, and of FR 75 and FR 10-sec for P-233. The completion of the FR or tandem requirement is indicated by a simultaneous slash on the cumulative response curve and an offset of the lower event line; a slash only on the cumulative-response curve indicates the elapse of the 6-min fixed interval. The records shown are from the last days of each condition. See text for an explanation of the schedules.

frequently exceeded 6 min and the period of initial responding was often positively accelerated. Once responding was initiated, it frequently occurred at a lower rate than under conjunctive FI FR (e.g., at those portions of the records marked c). Additionally, when responding was initiated prior to the elapse of the 6-min fixed interval, there was little or no evidence of the abrupt transition to a high rate, and subsequent transition to a lower rate seen under the conjunctive FI FR schedule. When performances stabilized, interreinforcement times under the conjunctive FI tandem schedule were longer than under the conjunctive FI FR schedule.

Figure 2 summarizes three measures of performance obtained in various phases of the experiment. Compared to performance under the fixed-interval schedule (stippled bars), pause durations were longer under both conjunctive schedules. Under the conjunctive schedule with the tandem requirement (open bars), response rates were generally lowest and pause durations and interreinforcement times longest. Under the conjunctive FI FR schedule (solid bars), interreinforcement times were comparable to those obtained under the fixed-interval schedule.
Changes in performance upon introduction of the tandem FR 50 FI 10-sec schedule were sustained for all pigeons except P-233. Subsequent variations in the FR requirement (FR 50 to 150) with this pigeon established performances comparable to those obtained with the other subjects at FR 75 (those values are shown in Figures 1 and 2). Table 2 shows that both pause duration and interreinforcement time were directly related, and response rate inversely related to the fixed ratio value. When the FR requirement was 150 , response rates were lowest and pausing and interreinforcement times were greatly extended.

Table 3 shows that under the conjunctive FI tandem schedule, reinforcement most frequently occurred upon completion of the tandem requirement, i.e., after the 6-min interval had elapsed. The frequency with which this occurred increased with continued exposure to the conjunctive schedule with the tandem FR FI (compare the first and last five sessions). In contrast, after continued exposure to the conjunctive Fl FR, reinforcement typically occurred when the 6-min interval elapsed, indicating that the FR schedule was completed before that time. Compared to the initial exposure to the conjunctive FI tandem schedule, 




Figure 2. Interreinforcement time (lower panel), pause duration (middle panel), and response rate (upper panel) under different schedule conditions. Stippled bars, FI; solid bars, conjunctive FI FR; open bars, conjunctive (FI 6-min) (tand FR FI 10-sec). The values of the schedules are as in Figure 1. Data are based on the mean of the last five sessions under each condition. Vertical lines denote +1 standard deviation. Note that response rate is considerably decreased and both pause and interreinforcement times are considerably increased under the conjunctive schedule with the tandem requirement.

Table 2

Effects of the Size of the Fixed Ratio of the Tandem Schedule on Performance of P-233 During the Last Five Sessions of Each Condition

\begin{tabular}{cccc}
$\begin{array}{c}\text { Ratio } \\
\text { Value }\end{array}$ & $\begin{array}{c}\text { Responses } \\
\text { per Second }\end{array}$ & $\begin{array}{c}\text { Pause } \\
\text { Duration }\end{array}$ & $\begin{array}{c}\text { Interreinforce- } \\
\text { ment Time }\end{array}$ \\
\hline $50^{*}$ & .85 & 177.5 & 361.0 \\
75 & .70 & 217.8 & 369.0 \\
150 & .41 & 423.8 & 590.4 \\
\hline
\end{tabular}

Note-Pause Duration refers to time in seconds to the first response averaged for a single cycle of the schedule. Interreinforcement time refers to total session time in seconds divided by the number of schedule cycles per session.

*Data are from the second exposure to this condition.
Table 3

Percent Reinforcement by Ratio or Tandem Schedules

\begin{tabular}{lcccc}
\hline & P-2W & P-10 & P-25 & P-233 \\
\hline \multirow{2}{*}{ tand following FI } & 9 & & 18 & \\
& 63 & & 69 & \\
conj FI FR following tand & $44^{*}$ & 43 & 63 & 23 \\
& $15 \dagger$ & 14 & 14 & 8 \\
tand following conj FI FR & 21 & 31 & 32 & 25 \\
& 59 & 69 & 48 & 45 \\
\hline
\end{tabular}

Note-Data represent the mean percentage of the time that reinforcement occurred according to either the FR or tandem FR FI schedule, that is, when the interval elapsed prior to the completion of these requirements for the first (top figure in each pair) and last (lower figure in each pair) five sessions. All values listed under $P-233$ are from manipulations with either FR 76 or tandem FR 75 FI 10 sec.

${ }^{*}$ Redetermined point $=47 . \quad$ TRedetermined point $=10$.

the second transition to this schedule was followed by a more rapid change in performance during the first five sessions.

Effects of varying the length of the fixed interval of the tandem schedule with P-25 are summarized in Figure 3. With decreases in fixed-interval length, response rate increased and pause duration and interreinforcement time generally decreased. When the fixed interval was $.1 \mathrm{sec}$, the above measures of performance approached those obtained under the conjunctive FI 6-min FR 51 schedule. Patterns of responding under various interval values are shown in Figure 4. Although measures of performance at the .1-sec FI were comparable to those obtained under the conjunctive FI 6-min FR 51 schedule (cf. Figure 3), the patterns of responding still differed. The initial high response rate seen under the conjunctive FI 6-min FR 51 schedule was either absent or less pronounced. In addition, there was an irregular alternation between schedule cycles with short pauses and higher response rates and those cycles with longer pauses and lower overall rates. With increasing fixed-interval durations, the pauses were increasingly longer than $6 \mathrm{~min}$, response rates after pauses were often lower, and there was little or no evidence of the pattern typically seen under conjunctive FI FR schedules.

\section{DISCUSSION}

In the present study, a reproducible pattern of responding developed under a conjunctive FI FR schedule which was characterized by an initial pause, an abrupt transition to a high response rate, and a subsequent transition to a lower rate (cf. Figure 1; see also Barrett, 1974, 1975; Herrnstein \& Morse, 1958). Under the conjunctive FI tandem schedule, the pattern of responding was considerably different. Introduction of the tandem schedule requirement either abolished or precluded the development of the 


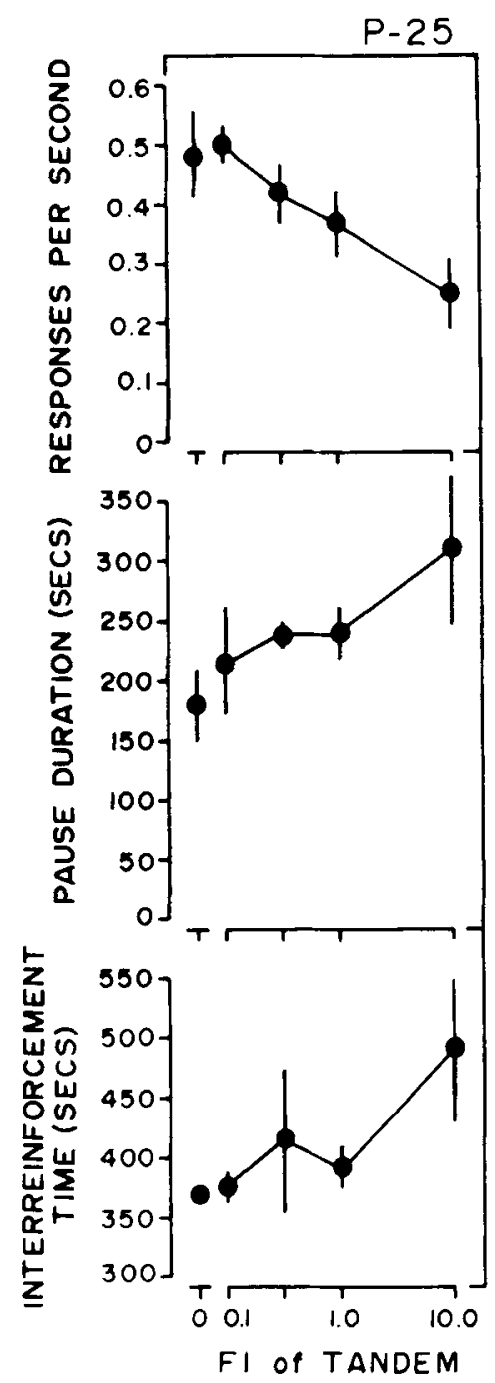

Figure 3. Effects of duration of the FI of the tandem schedule on interreinforcement time (lower panel), pause duration (middle panel), and response rate (upper panel) for P-25. Unconnected points represent those values obtained under the conjunctive FI FR. Data are based on the mean of the last five sessions under each condition. Vertical lines denote \pm 1 standard deviation.

abrupt transition from pausing to responding at a high rate. Additionally, the length of the pause was increased and there was a more gradual increase in rate once responding began.

As the duration of the FI of the tandem requirement was decreased, performance under the conjunctive schedule approached that obtained under conjunctive FI FR. At the shortest duration studied $(.1 \mathrm{sec})$, interreinforcement times were comparable to interreinforcement times under FI and under conjunctive FI FR. Mean response rates and pause durations were also comparable to those obtained under conjunctive FI FR. Patterns of responding seen in the cumulative records, however, were intermediate between those obtained under the FI and the conjunctive FI FR; there was some evidence of the pattern typically obtained under conjunctive FI FR, but the transitions between aspects of performance were not as clearly defined.

When duration of the FI of the tandem schedule was $10 \mathrm{sec}$, once responding began it was often positively accelerated. As in other studies (Barrett, 1975; Kelleher \& Morse, 1969), this pattern of responding developed under conditions in which interreinforcement times were variable. While positive acceleration of responding reliably develops under conditions in which interreinforcement times are constant (Dews, 1970), constancy of interreinforcement times is not necessary for the development of this pattern of responding.

The conjunctive FI tandem schedule required the same minimum number of responses as the conjunctive FI FR, but insured that reinforcement never directly followed completion of the FR requirement. Upon initial introduction of this conjunctive schedule, only between $10 \%$ and $20 \%$ of the reinforcements were provided according to the tandem schedule; these frequencies are only slightly higher than those observed by Herrnstein and Morse (1958) during $45 \mathrm{~h}$ of exposure to conjunctive FI FR. Under the conjunctive schedule with the tandem requirement, however, the percentage of reinforcements according to the tandem schedule increased and response rates decreased markedly. When the FI of the tandem schedule was removed (changing the schedule to conjunctive FI FR), the patterns of responding typically seen under conjunctive schedules developed. The present findings thus indicate that merely specifying a required number of responses is not sufficient to establish the pattern of responding obtained under conjunctive FI FR, and add support to the interpretation by Herrnstein and Morse (1958) that the initial

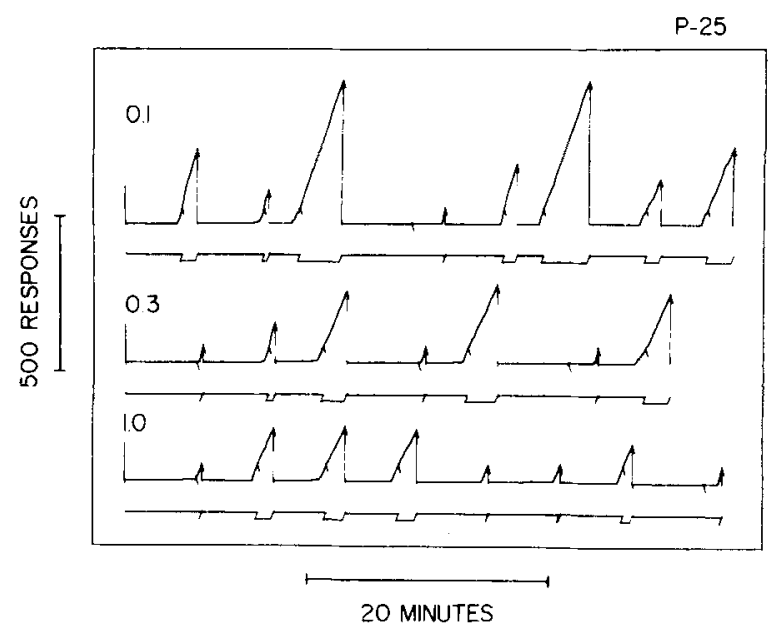

Figure 4. Cumulative records of responding under the conjunctive (FI 6-min) (tand FR 50 FI t-sec) schedule for P-25. The values (in seconds) for the FI of the tandem schedule are shown at the upper left of each record. Abscissae, time; ordinates, cumulative responses. Recording is as in Figure 1 . The records are portions of the last sessions under each condition and from the first exposure to each schedule. 
high response rate under conjunctive FI FR is maintained by the infrequent reinforcement provided directly by the FR schedule.

Under FI schedules, many responses are emitted repeatedly throughout the interval. A change from FI to conjunctive FI FR typically decreases responding (Barrett, 1975; Herrnstein and Morse, 1958), indicating that FI schedules generate substantial responding, in part due to their relatively slight demands (Herrnstein \& Morse, 1958). When certain response requirements are added to an FI schedule that preclude direct reinforcement according to FR contingencies, responding is decreased even further than under conjunctive FI FR. This indicates that the decreasing effects on FI responding of added response requirements are modulated by the prevailing contingencies at reinforcement.

\section{REFERENCES}

Barrett, J. E. Conjunctive schedules of reinforcement I: Ratedependent effects of pentobarbital and d-amphetamine. Journal of the Experimental Analysis of Behavior, 1974, 22, 561-573.
BARretT, J. E. Conjunctive schedules of reinforcement II: Response requirements and stimulus effects. Journal of the Experimental Analysis of Behavior, 1975, 24, 23-31.

DEws, P. B. The theory of fixed-interval responding. In W. N. Schoenfeld (Ed.), The theory of reinforcement schedules. New York: Appleton-Century-Crofts, 1970.

Ferster, C. B., \& Skinner, B. F. Schedules of reinforcement. New York: Appleton-Century-Crofts, 1957.

Herrnstein, R. J., \& Morse, W. H. A conjunctive schedule of reinforcement. Journal of the Experimental Analysis of Behavior, 1958, 1, 15-24.

Kelleher, R. T., \& Morse, W. H. Schedules using noxious stimuli IV: An interlocking shock-postponement schedule in the squirrel monkey. Journal of the Experimental Analysis of Behavior, 1969, 12, 1063-1079.

Morse, W. H. Intermittent reinforcement. In W. K. Honig (Ed.), Operant behavior: Areas of research and application. New York: Appleton-Century-Crofts, 1966.
(Received for publication December 22, 1978;
revision accepted April 5, 1979.) 